\title{
Sobre Protágoras e Platão: divergências e convergênCias ACERCA DO FRAGMENTO DO HOMEM-MEDIDA
}

\author{
[ On Protagora and Plato: Divergences and CONVERgences about the Fragment of \\ HUMAN-MEASURE ]
}

Ana Rafaella Pereira Melo * Faculdade Brasileira de Ensino, Pesquisa e Extensão, Brasil

\author{
Iraquitan De Oliveira Caminha ** \\ Universidade Federal da Paraíba, Brasil
}

Resumo: Protágoras de Abdera, conhecido sofista da Grécia antiga, é compreendido em seus dizeres no decorrer da história da filosofia principalmente devido às contribuições de Platão. $\mathrm{O}$ ateniense não apenas dedicou uma obra com seu nome, como também apresentou sua famosa tese do homem-medida no diálogo Teeteto, contribuindo imensamente para elucidar questões importantes sobre seu relativismo. O quão seria pertinente afirmar que é possível saber na íntegra o que queria dizer Protágoras nesse fragmento quando seguimos apenas os testemunhos de Platão. No presente trabalho, iremos propor algumas interpretações dos fragmentos de Protágoras de Abdera com a finalidade de percebermos se há divergências com a interpretação platônica, acima de tudo sobre o fragmento do homemmedida. Traremos, para a análise de Protágoras, o livro de Edward Schiappa, Protagoras and Logos, fazendo as devidas considerações sobre suas conclusões, para, ao final da pesquisa, nos posicionar devidamente diante do que Platão, de fato concordou e acertou sobre o homem-medida.

Palavras-chave: Protágoras; Platão; homemmedida; percepção; logos
ABSTRACT: Protagora from Abdera, known as an ancient greek sophist, is understood in his writtings during the history of philosophy specially because of Plato's contributions. The athenian not only dedicated a whole work with his name as he also presented his famous human-measure thesis on the dialogue Theaetetus, contributing highly to clarify important issues about his relativism. How much would be relevant to claim that is possible to know in full what Protagora meant with this fragment when we only follow Plato's testimony. At the present work, we are about to propose some interpretations about Protagora's fragments for the purpose to realize if there are divergences with Plato's interpretation, above all about the human-measure fragment. We will bring, for the Protagora's analysis the Edward Schiappa's book, Protagoras and Logos, pointing due considerations about his conclusions for, at the end of the research, take a properly position against of what Plato really agreed and hit about the human-measure fragment.

KeYwORDS: Protagora; Plato; human-measure; perception; logos

\section{Considerações INICIAis}

Tendo em vistas o Teeteto de Platão e a investigação que é realizada na obra sobre o ponto de vista de Protágoras e seu relativismo, propomos colocar em debate a interpretação platônica do abderita e os estudos dos fragmentos de Protágoras, usando como base os comentários de Edward Schiappa em seu livro

* Doutora em Filosofia pela Universidade Federal da Paraiba, UFPB, Brasil. m@ilto: arafaellapm@gmail.com.**Doutor em Filosofia.Professor do Programa de Pós-Graduação em Filosofia da Universidade Federal da Paraiba, UFPB, Brasil. m@ilto: caminhairaquitan@gmail.com 
Protagoras and Logos, a partir do qual ele elabora possibilidades de interpretar Protágoras sob a luz de sua época para verificarmos a pertinência de Platão em sua discussão sobre 'o homem-medida'. É importante observar que Platão pode ter dado a Protágoras uma interpretação não muito fiel, apesar de que o ateniense não pode deixar de ser considerado enquanto fonte de conhecimento do pensamento do sofista. De acordo com Schiappa, muito do que sabemos sobre Protágoras advém dos diálogos platônicos Teeteto e Protágoras. Porém, alguns pensadores da literatura platônica acreditam que o ateniense pode ter deliberadamente distorcido o pensamento de Protágoras para que se tornasse mais fácil sua refutação. Dentre outras acusações de má interpretação de Protágoras por Platão, algumas afirmam que ele pode realmente não ter compreendido a teoria do abderita, mas tentou reproduzi-la da melhor maneira possível. Ao final desse artigo, traremos algumas considerações sobre a interpretação de Platão em confronto com o que foi apresentado em análise sobre os dizeres do próprio Protágoras.

No livro em questão, é discutida a mudança entre oralidade e discurso escrito, sendo observadas as tentativas dos filósofos pré-socráticos até Platão em ressignificar termos comumente utilizados, como virtude, justiça, discurso, etc. Houve uma mudança no que concerne não somente à mitologia em direção a um saber racional, como também da oralidade para a escrita, bem como o sentido e ampliação de termos introduzidos nos discursos. Os discursos precisavam ainda carregar uma atrativa maneira de ser escutada. Poemas, aforismos e diálogos devem fazer parte. Somente Aristóteles incorporou o verdadeiro discurso analítico.

\section{Primeiro fragmento PARA A discussão: DisSoi logoi}

O primeiro fragmento que iremos trazer para discussão do livro de Schiappa será o conhecido por disso logoi, que remete essencialmente ao fato de que para toda coisa (panta pragmata) - questão, assunto, toda coisa - existem dois logoi (discursos) contraditórios ou em oposição um ao outro. O problema de atribuir a esse fragmento um significado determinado está na impossibilidade de determinar sobre o que exatamente Protágoras falava quando disse logoi e panta pragmata. De acordo com Schiappa, a interpretação subjetivista dá ao fragmento o entendimento de que sobre qualquer questão é possível que ocorra um debate, abrindo espaço para fundamentar os ensinamentos a partir da qual partem aqueles que dizem ser o pensamento protagoreano voltado para a retórica. A seguir, um exemplo da tradução que segue essa linha de interpretação: "Em cada assunto, existem dois argumentos opostos um ao outro."1 Seguindo essa linha de interpretação, logoi e pragmata são entendidos como discursos ou argumentos e assunto ou questão, respectivamente. Sendo pragmata um assunto ou questão, isso implica que são criações humanas assim como os discursos a isso atribuídos. Tudo isso significa que o que há de ser identificado em algo é uma criação do homem, criação linguística que implica em variáveis resultados, bem como no campo da ética e da epistemologia. Melhor dizendo, não há aspectos identificados do objeto mesmo, resultante de uma investigação, mas uma criação proveniente daquele que argumenta em favor daquilo que lhe apetece na dada questão.

Para a linha de entendimento que segue Heráclito, Schiappa aponta que as traduções dadas aos termos supracitados são mais abrangentes devido à consciência de aspectos filosóficos a eles relacionados. Temos que "Existem dois logoi que concernem a todas as coisas, estes sendo opostos um ao outro"(SCHIAPPA, 2003, p. 91). A escolha por não traduzir o termo logoi se dá devido ao amplo espectro de assuntos a ele relacionados na Grécia antiga. Logos podia ser entendido como discurso linguístico, 
argumento, fala, bem como pensamento, processo mental, explicação, e ainda quando se trata da questão da estrutura de tudo o que existe, sua lei, fórmula e princípios do processo do mundo. A palavra deve ser traduzida de acordo com o seu contexto que, mesmo sendo claro e específico, a multiplicidade de sentidos atribuídos a ela ainda pode tornar difícil a decisão por uma ou outra tradução. Como veremos logo a seguir, Untersteiner verifica que Protágoras foi um pensador sobre variados temas, ampliando as possibilidades das palavras por ele usadas. Logos, como vimos, no item relacionado a Heráclito, tem sentidos múltiplos para os gregos antigos, e os mais aparentes no período do abderita eram:

(...) primeiramente na área da linguagem e formulação linguística, consequentemente discurso, fala, descrição, declaração, argumento ( como expressado em palavras ) e assim por diante; em segundo lugar, a área do pensamento e processos mentais, consequentemente pensar, racionalizar, calcular, explicação (cf. ortho logos ), etc; em terceiro lugar, a área do mundo, sobre as quais estamos aptos a falar e pensar, consequentemente estruturando princípios, fórmulas, leis naturais e assim por diante (...).( KERFERD, 1981, p. 83)

Nessa linha interpretativa, a palavra pragmata sugere um entendimento amplificado de realidade, podendo isto ser um fato, uma coisa, um ato ou qualquer experiência. Segundo Schiappa, é de melhor aceitação o entendimento do fragmento por essa linha de interpretação, dado que aspectos modernos que distinguem subjetividade de objetividade não eram claramente discernidos nessa época, podendo estarem ambas as compreensões intrínsecas ao intento do abderita. A interpretação subjetivista propõe uma limitação ao termo pragmata como sendo uma questão ou assunto, entendimento um tanto moderno que talvez não seja adequado para $o$ pensamento dos gregos antigos. É mais provável, devido ao nível filosófico dos debates da época, que pragmata e logoi sejam interpretados de maneira mais ampla. Pragmata era mais comumente traduzido nos documentos do período de Protágoras como "coisas", e contando com isso, agreguemos também a interpretação de Untersteiner (UNTERSTEINER, 1954) sobre Protágoras, que afirma que o abderita falou sobre as mais variadas questões, incluindo a divindade, realidade, política, sociedade e ética. Dada à riqueza dos tópicos por ele abordados, seria pertinente seguir a hipótese de que pragmata em Protágoras também deve manter o significado de 'coisa', que remete a uma abrangente gama de possibilidades. Essa amplitude carrega ainda mais um aspecto positivo para a escolha dessa interpretação, dado sua semelhança com o pensamento de Heráclito, a partir da qual duas coisas opostas existiam em tudo o que há. Vejamos essa alusão a seguir.

Pré-socráticos como Alcmeon, Anaxímenes, Empédocles, dentre outros, teorizavam acerca de opostos constituintes das coisas na natureza, utilizando um adjetivo neutro para se referir a eles, tornando-os mais abstratos. $\mathrm{O}$ calor e o frio, a água e o fogo, estavam na natureza, eram substâncias opostas que compunham as coisas postas no mundo. Heráclito foi o maior representante da teoria dos opostos, como pudemos ver nas discussões acima. Com isso, ele afirma que a unidade dos opostos é o que compõe tudo o que há, que cada coisa no mundo representa essa abstração, representa a oposição, inerente à natureza mesma. Podemos dizer que Protágoras estaria seguindo Heráclito ao considerar que, para cada coisa que co-instancia os contrários, existem dois logoi possíveis, contrários um ao outro. Dois logoi opostos um ao outro que podem ser reconhecidos, ditos, considerados enquanto composições das coisas; seria pertinente dizer que Protágoras herdou de Heráclito a concepção de que as coisas têm em sua composição a unidade dos opostos em harmonia e esses dois logoi são o discurso que trata sobre o reconhecimento desses opostos na coisa? A ampliação do 
pensamento de Heráclito por Protágoras seria a inclusão da ferramenta do discurso para dar sentido à unidade dos opostos, considerando que eles podem ser afirmados e negados. O fragmento do dissoi logoi preserva uma afinidade com o fragmento que trataremos a seguir sobre o mais forte e mais fraco logoi, que claramente trata de uma maneira peculiar de usar o discurso, mostrando a preocupação do abderita em construir um melhor entendimento sobre as possibilidades da linguagem. Não há como restringir a interpretação de dissoi logoi apenas ao discurso, como pretendeu a interpretação subjetivista, mas conceber tal fragmento como herança heracliteana com sua devida ampliação. O discurso também é um assunto sobre a qual Protágoras dedica atenção. Essa possibilidade de aproximar Protágoras de Heráclito também é notável, dado que alguns intérpretes como Clemente de Alexandria, Aristóteles e o próprio Platão consideraram o dissoi logoi como referência direta aos ensinamentos da unidade dos opostos de Heráclito.

Schiappa argumenta em favor de uma profissionalização e "tecnização" da linguagem por parte de Protágoras no fragmento do dissoi logoi, além de seguir Heráclito, afirmando haver dois logoi para todas as coisas. Parece algumas vezes que Protágoras tinha evidente interesse em trabalhar a linguagem como mecanismo importante para o homem. O fragmento em questão seria, dessa forma, para falar sobre como as coisas são, a relação entre coisas que são e linguagem. Se é possível dizer A e não-A sobre uma e mesma coisa, então esses predicados são estados que compõem tal coisa. É possível observar interpretações com focos diversos quando se lê Clemente de Alexandria, Sexto Empírico, Aristóteles e Platão. Sexto dizia que os logoi subsistiam na matéria; Aristóteles afirmou que para uma mesma coisa, ambos são e não são, indicando uma interpretação composicional para Protágoras; Clemente de Alexandria dizia que cada logos tem seu oposto e Platão dizia que uma coisa pode aparecer pequena e também aparecer grande como que um predicado, uma atribuição. Vemos assim que é possível que Protágoras tenha inaugurado uma relação posteriormente vislumbrada pelos seus intérpretes, que falava de uma configuração linguística racional sobre a natureza de tudo o que é e aparece.

Talvez seja imprudente dizer que Protágoras quis dar um passo entre a natureza essencial das coisas e as leis da lógica proposicional, mas ao menos podemos ver que ele abriu caminho para essa possibilidade. É inadequado querer dar uma interpretação definitiva e distinta sobre o fragmento em questão, dado que não é possível identificar qual o real significado dos termos principais em foco no fragmento, a saber, pragmata $\mathrm{e}$ logoi.

Outro fragmento considerado muito importante no pensamento de Protágoras e com estreita relação com o do homem-medida é o que trata dos logoi mais forte e o mais fraco. Vejamos.

\subsection{O fragmento do logoi mais forte e o mais fraco}

O fragmento completo é encontrado na Retórica de Aristóteles e é considerado por W. K. C. Guthrie enquanto sendo a essência do ensinamento da sofística. De acordo com Schiappa, a tradução mais distorcida do fragmento pertence à Lane Cooper, que diz: "fazendo a pior aparecer a melhor causa". Duas palavras aparecem como sendo estranhas ao legítimo fragmento, que é "causa" e "aparecer". Essa tradução de Cooper representa tudo aquilo que a tradição reconhece como sendo inescrupuloso da parte dos sofistas, pois o apresenta enquanto aquele que trabalha com o discurso de maneira amoral. Representa acima de tudo o slogan popular que mostra as piores aspirações do movimento sofístico e talvez a arte da retórica mesma. É uma tradução que deprecia a 
figura dos sofistas e retrata resumidamente a tentativa platônica de se opor a eles.

Essa tradução de Cooper ao fragmento de Protágoras é a base do que ele chama de interpretação aristotélica pejorativa e tem como principais problemas a inserção da palavra "aparecer", que não está no fragmento original (phainetai, aisthanomai), e da tradução da palavra logos por "causa", dada a abrangência do termo já discutida neste trabalho. Um terceiro problema tem como foco a tradução de kreittô e hêttô como "melhor" e "pior". As palavras chave do fragmento, kreittô e hêttô, são melhores traduzidas por meio da análise de seu uso na época de Protágoras como sendo o "mais fraco" e o "mais forte." Traduzi-las enquanto melhor e pior carrega uma acentuação moral ampla que deixa claro que ocorre uma inversão no valor do "argumento", tornando o que não é bom, uma boa coisa, sugerindo que havia uma motivação perversa por parte de Protágoras, de trazer o mal para o lugar do bem. Se traduzirmos como mais forte e mais fraco, isso não implica que o mais fraco venha a ser o pior, mas apenas fraco devido a determinadas circunstâncias. Nos escritos de Homero e no Timeu de Platão, kreittô e hêttô aparecem juntas como significando o que é forte, mais resistente, e o que é mais fraco, que se submete a, que não tem força. A tradução dos termos como sendo melhor e pior somente aparece mais a frente, em alguns diálogos de Platão e em Aristóteles.

Dado o contexto provido por Aristóteles a esse fragmento e a escolha de "melhor" e "pior" para kreittô e hêttô, podemos observar interpretações carregadas de nuances lógicas e morais, tal como a de E. M. Cope, a partir da qual ele afirma que "dando o superior ao inferior, o argumento menos provável, faz com que este prevaleça sobre o que é realmente superior e mais provável" (COPE, 1877). De acordo com Schiappa, as elucidações aristotélicas sobre os fragmentos dos sofistas eram apresentados de maneira a torna-los ultrapassados em relação à sua filosofia, sempre contrastando a doutrina deles com seu próprio sistema. O modo de interpretação aristotélico pejorativo é consistente com a maneira como Aristóteles entendeu os sofistas, mas não há nenhuma razão para considerar essa interpretação superior às outras alternativas. Platão e Aristóteles, que construíram a visão tradicional acerca dos sofistas perante a história da filosofia, tinham seus pontos de vista delineados e aparentemente estranhos ao de Protágoras, com objetivos pessoais de contrastarem o pensamento do abderita com suas próprias filosofias. Por essa razão, é compreensível que o entendimento sobre a sofística seja normalmente depreciativo, dado a importância do pensamento do ateniense e do estagirita na história da filosofia. Mas, tendo em vistas essa possibilidade, devemos direcionar nossa atenção para uma interpretação mais original de Protágoras, que tentará trazer o que parece ser sua real "promessa".

O diferencial da interpretação positiva do fragmento é a tradução de kreittô e hêttô enquanto "o mais forte" e "o mais fraco". Essa tradução se aproxima do contexto histórico dos debates e apresenta um ensinamento de Protágoras que tem a intenção de desafiar a relação entre dois logoi em conflito. Esses dois logoi podem ser relacionados com o fragmento do dissoi logoi e aproximado aos ensinamentos de Heráclito sobre o fluxo.

A interpretação positiva do fragmento contrasta com a pejorativa aristotélica. Dado que Aristóteles deixou o legado protagoreano corrompido por uma conduta antiética que tentava perverter a ordem do melhor por meio do discurso, isso entra em contradição com a reputação do abderita, inclusive elaborada em parte pelo próprio Aristóteles, de que Protágoras era eticamente conservador e tradicionalista. Ele era virtualmente conhecido por essas características, consideradas válidas também por Platão, que apesar dos conflitos evidentes contra os sofistas, reconheceu o valor e importância da pessoa que Protágoras representou em seu tempo. Portanto, contra a interpretação aristotélica pejorativa, temos aspectos linguísticos não compatíveis com 
os escritos e pensamentos da época de Protágoras e aspectos contraditórios sobre o que ele teria ensinado e sua conduta moral reconhecida. Partiremos agora para a aproximação com os ensinamentos de Heráclito.

É bastante elucidativo a comparação que Schiappa faz entre a harmonia dos opostos de Heráclito e o que os médicos da época compreenderam a respeito, incorporando esse pensamento à sua ciência. Eis a visão de Heráclito a partir do ponto de vista da medicina grega: mudança de opostos, na medida em que a saúde de algo pode vir de seu oposto. Trazendo para a enfermidade aquilo que é seu oposto por natureza, restituirá a saúde. É um fluxo que transita entre o que aparece como sendo necessário na ocasião. Se a cura para a fome é o saciar-se, a cura para o empanturrado é trazer de volta a fome. O paralelo que Schiappa mostra entre a teoria dos médicos e Protágoras é o de que para trazer a cura, é preciso fazer do oposto mais fraco, o mais forte. Essa é uma evidência de que a aproximação do fragmento do logos mais forte e mais fraco ao fluxo de Heráclito é possível. Para estabelecer a harmonia do corpo doente, faz-se necessário o movimento do oposto mais fraco a tornar-se mais forte. Estão juntas aí as noções de movimento, de opostos, de harmonia e do mais fraco e do mais forte logos. Essas aproximações tornam-se possíveis, dado o contexto histórico de tais pensadores, a partir da qual uma teoria que envolve noções embrionárias de mudança e uma ontologia dos opostos eram debatidas.

A defesa de Protágoras no Teeteto mostra fortes evidências para conciliar essa aproximação, pois nela claramente o abderita lida com logos, tornando o mais forte, mais fraco; o fortalecimento de um logos preferível, porém ocasionalmente mais fraco, em virtude de um logos não preferível no momento, porém mais forte: "O que é desejado é a mudança para a condição oposta" (PLATÃO, Teeteto, 166d). No fragmento 52 de Heráclito há uma noção embrionária de mudança nos opostos, tal como vemos interpretar os médicos e também Protágoras com sua alteração do argumento mais forte para o mais fraco. "As coisas frias esquentam-se, o quente esfria-se, o úmido seca, o seco umidifica-se" (HERÁCLITO, 2011). Se é plausível essa aproximação, então a interpretação positiva do fragmento, a partir da qual podemos tirar a lição de tornar um argumento fraco, mais forte, melhorando uma situação, ganha novos reforços. Se Protágoras realmente seguiu Heráclito quando formulou o fragmento dos dois logoi, não é improvável, pelo contrário, é provável que o tenha seguido também na composição de outros pensamentos.

Não optar pela interpretação aristotélica tem também fundamento quando analisamos Aristófanes e suas conclusões sobre Protágoras. Com a análise sobre Aristófanes, Schiappa pretende mostrar como é possível mal interpretar Protágoras, inclusive da mesma maneira que Aristóteles, sobrepondo em seu fragmento aspectos morais. Aristófanes utilizou-se de Sócrates como personagem para satirizar os Sofistas, mas existem várias evidências de que os ensinamentos de Protágoras é que estavam sendo acentuados enquanto pervertores da ordem tradicional da polis. É evidente também que Aristófanes fazia uma crítica a essa perversão trazida pelos sofistas, que corrompiam os deuses, a moralidade, o saber e as artes. Protágoras usou palavras de fácil recordação, inclusive a homofonia que ocorre entre kreittô e hêttô, trazendo com isso uma ampla possibilidade de más interpretações.

As Nuvens, sátira escrita por Aristófanes em meados dos anos 300 a.C. tem como principal conflito dramático o combate entre dois logoi personificados, um representando a educação e devoção tradicionais, e o outro representando os novos ensinamentos sofísticos. Existem versões da peça que carregam esses dois logoi como descritos por Dikaios e Adikos, que é geralmente traduzido como justo e injusto, certo ou errado. Alguns comentadores recentes consideram que Dikaios e Adikos foram colocados posteriormente no texto, não tendo sido palavras utilizadas por Aristófanes. 
Embora não seja unânime essa consideração, existem pelo menos três manuscritos que contém kreittô e hêttô como substitutas de Dikaios e Adikos. Algumas evidências internas na peça fortalecem a possibilidade do uso de kreittô e hêttô: a expressão dikaios logos nunca aparece nos diálogos entre as personagens, e quando há menção ao logos injusto, essa sempre é precedida pela referência aos dois logoi como sendo kreittôn logos e hêttôn logos. Outra evidência, essa extra textual, é a da profundidade do sentido de um logos injusto na peça de Aristófanes que seria requerida pelo uso da palavra dikaios. Fica claro que o sentido que Aristófanes usa para falar de justo e injusto é o que aparece nos escritos de Homero, como sendo justo pagar pelo que fez, e o injusto como sendo a esquiva desse pagamento. Dikaios provém do termo dikaiosunê, que tem um sentido amplo de justiça enquanto virtude, utilizado por Platão em seus diálogos. Aristófanes se referia a justiça como uma coisa de ordem pragmática, de fazer justiça de acordo com atos através de atos. Não há abstração do termo nesse contexto. Os Sofistas representam de certa forma, nas Nuvens, a força da injustiça, por estarem em débito com Atenas, dado que prometiam ensinar algo que não ensinavam de fato: conhecimento e virtude.

O combate mais conhecido entre os dois logoi se refere a uma batalha de palavras e de modos de vida. A tradição da polis, aquela que conservava a devoção aos deuses, à mitologia, ao ensino tradicional de poesia e à música, bem como o respeito aos cidadãos mais velhos é ameaçada por um modo de vida que traz, por meio do hêttôn logos, uma substituição do kreittôn logos. O hêttôn logos, promove desafios à música, a poesia é instigado pela argumentação racional, a mitologia é desafiada pelo agnosticismo e o cinismo incorpora um niilismo moral que desafia os valores tradicionais. O veículo da propagação desses ensinamentos eram os sofistas, cuja ferramenta era o discurso persuasivo. Embora claramente contra os sofistas no geral, Aristófanes traz elementos exclusivamente protagoreanos em seus ataques. $\mathrm{O}$ agnosticismo faz referência ao fragmento "sobre os deuses" do abderita; um bom número de frases se referem aos dois logoi em oposição; há uma piada sobre o termo metron, que é o termo central no fragmento do homem-medida; duas passagens que se referem indiretamente ao fluxo e a harmonia dos opostos, além do uso das palavras kreittôn e hêttôn, que aparece em Aristófanes como sendo autenticamente protagoreano, na medida em que trata de um discurso persuasivo que fortalece um logos em oposição a outro, fazendo com que haja a partir daí uma mudança no modo de vida.

Portanto, a visão de Aristófanes só faz sentido se considerarmos razões morais como intentos primordiais nos dizeres do abderita e em contextos como o de Aristóteles. Dado o sentido das palavras-chave do fragmento que era mais comum no século 500 a.C. a melhor tradução para elas é mais forte e mais fraco, destituindo-as de conexão com a moralidade, caracterizando assim a interpretação positiva enquanto a mais provável.

\subsection{O fragmento do homem-medida}

"O homem é a medida de todas as coisas, das coisas que são como são, das coisas que não são como não são" é a versão mais comum do fragmento do homemmedida de Protágoras. Schiappa sugere que este seja traduzido do seguinte modo: “ Para toda e qualquer coisa a medida é (verdadeiramente) o homem (humanidade): para o que é o caso e para o que não é o caso.” (PROTÁGORAS, 2003, p. 120) Vejamos as razões.

Deve-se, acima de tudo, como foi feito na análise dos fragmentos anteriores, observar qual era o uso corrente dos termos contidos no fragmento, naquela época. As 
palavras que podem conter variados significados no fragmento em questão são chrêmata, (pantôn chrêmatôn), metron, estin/einai, anthrôpos. Chrêmata aqui deve ser caracterizado por algo que tenha o mais amplo alcance de objetos, dado que é precedido pelo termo pantôn, e levando também em consideração que seus significados mais comuns são igualmente abrangentes, tais como assunto, bens, propriedade e matéria. É evidente não ser possível precisar a razão pela qual o abderita usou chrêmata ao invés de pragmata, mas deve-se considerar que, referindo-se a um amplo alcance de coisas, incluindo tudo o que está em relação com humanos, podemos entender que o mais próximo daquilo que ele pretendeu no fragmento foi referir-se a experiências.

Metron é usado pelos gregos para referir-se a mensura de quantidades, proporção ou ordem. Heráclito usa o termo para destacar a medida, balanço da ordem na harmonia dos opostos. O modo como Protágoras usa o termo no fragmento em questão é provocativo, dado que não parece referir-se a situações em que este termo servia normalmente. Sexto Empírico fez uma equivalência entre o termo metron com kritêrion para destacar o homem como o critério que julga as coisas em relação a ele. Assim também falaram Aristóteles e Platão, aplicando o significado de critério ou padrão para o uso do termo do homem enquanto medida daquilo que é. O que não fica claro por meio da análise centrada num único fragmento é que Protágoras concebia o homem enquanto aquele que julga as coisas, mas a percepção pode ou não ter sido a única levada em consideração para esse julgamento.

Schiappa aborda um questionamento referente ao advérbio de relatividade hôs que precede o uso do verbo estin, e que é comumente traduzido por "como" ou "que", abrindo espaço para interpretações existencialistas ou essencialistas do fragmento. (...) tôn mén onton hôs estin, tôn de ouk onton hôs ouk estin. Estaria Protágoras afirmando que as coisas existem na medida em que são julgadas pelo homem ou que o homem diz as essências das coisas? Embora existam muitos intérpretes que defendam os dois, Schiappa segue a alternativa de que uma leitura existencial do verbo ser naquela época é questionável, abrindo espaço para uma leitura veritativa do fragmento. Parmênides fez uma utilização do verbo ser bastante peculiar, mas não é claro que seus leitores a tenham apreendido verdadeiramente; e a suposta crítica a Parmênides sugerida por Schiappa, que Protágoras intentou fazer, afirma que sua leitura e entendimento do eleata não alcançou essa vertente de interpretação de estin. Dessa maneira, seria o caso de considerar o que Schiappa está propondo: que Protágoras fala de coisas no geral, bem como experiências, pois é tudo que se relaciona com o homem, podendo daí estabelecer uma interpretação veritativa do fragmento, a partir da qual se pode atribuir a tradução "that which is, that is the case", ou "que é o caso", na medida em que pode-se verificar na experiência aquilo que foi julgado pelo homem. Usando uma terminologia moderna, podemos dizer que o particípio to on representa um fato arbitrário, e hôs esti representa uma proposição arbitrária, sempre referindo a fatos e experiências que um homem pode ter e seu respectivo julgamento.

Anthrôpos carrega duas possibilidades: um homem individual e o homem universal que, de acordo com a maioria dos intérpretes, Protágoras esteve falando sobre ambos, cabendo ao fragmento qualquer delas.

Então "Of everything and anything the measure [truly-is] human[ity]: of that which is, that is the case; of that which is not, that is not the case." (SCHIAPPA, 2003, p. 120) Traduzido ao "pé da letra", temos que "De tudo e qualquer coisa a medida é verdadeiramente o humano, do que é, que é o caso; do que não é, que não é o caso", eis a proposta de Schiappa. O nosso próximo passo é, portanto, considerar o fragmento identificando possíveis novos usos e interpretá-los à luz dos antecedentes conceituais prováveis. Porfírio (SCHIAPPA, 2003, p.121) afirma que o fragmento em questão abria um escrito cuja temática central era um confronto contra aqueles que propuseram o ser 
como uno, que nos remete imediatamente aos eleatas, seguidores da doutrina de Parmênides.

Pareceu-me muito furtivo o argumento de Schiappa sobre a crítica de Protágoras a Parmênides, pois nele, o abderita apenas diria o contrário de algumas coisas ditas por Parmênides e pelos eleatas, sem entrar num esclarecimento acerca das razões sobre as quais os eleatas estariam errados. Para estes últimos, só o ser é, e para o abderita, o homem diz o que é e o que não é. É como se Protágoras estipulasse que o ser está nas coisas deste mundo percebido pelos mortais, reafirmando o que foi a base da crítica de Parmênides, a saber, que se pode dizer o que é e o que não é sobre uma e mesma coisa, além de considerar apenas o ser, aquele fenômeno que se encerra em si mesmo, na existência material. Protágoras, sendo assim, apenas retornou ao modo de proceder dos pré-socráticos a quem Parmênides estaria direcionando uma crítica no modo de "filosofar".

Protágoras articula uma defesa em nome do fato de haver ser e verdade no argumento que propõe, a saber, que o homem determina o que é e o que não é através dos fragmentos dos dois logoi e do homem-medida. A teoria de Parmênides assimila a verdade no caminho daquele que apenas fala do ser e o reconhece. Protágoras admite que é completamente aceitável falar do intercâmbio dos opostos e da mudança, aceitando a maneira antiga de entender o real. O real é apenas isso que se manifesta para o homem, sendo a partir dele que será dito o que é e o que não é. Os sentidos de ser de Protágoras não estão declarados. Schiappa segue alguns intérpretes que asseguram o uso do verbo ser em Protágoras como referente de ser "o caso", não existencial, mas veritativo. Se "é o caso", isso implica um fundo de experiência, empiria, prática, fato.

Partiremos agora para a interpretação relativista do fragmento do homemmedida, que aparece no Teeteto e nos é bastante familiar, também defendido por Sexto Empírico.

\subsection{Relativismo em Protágoras}

A ideia de relativismo pode ter estado presente na formulação do fragmento em questão e essa possibilidade é clara no exemplo de Plutarco sobre uma discussão entre Protágoras e Pericles. Posteriormente é desenvolvida por Platão, que enfatiza a percepção como o campo a partir da qual o relativismo é possível e mais enfaticamente apresentada por Sexto e sua compreensão do abderita a partir de Platão e Aristóteles. O exemplo de Plutarco é descrito por Schiappa.

Um jovem rapaz, Epitimo de Farsalo, foi acidentalmente morto com um dardo. Pericles e Protágoras supostamente desprenderam um dia inteiro tentando decidir se deviam considerar a causa da morte como sendo o dardo, o homem que lançou ele, ou o supervisor responsável pelo campo.(...) Para um médico, a melhor resposta seria o dardo; para o juiz da corte, a melhor resposta seria a pessoa que o jogou; e para o administrador, a melhor resposta seria o supervisor. Nenhuma resposta pode ser julgada como a correta em nenhum abstrato ou absoluto sentido, mas apenas relativo a necessidades e interesses de pessoas diretamente envolvidas na experiência. (SCHIAPPA, 2003, p. 126)

Essa ideia apresenta a relação que há entre fatos e pessoas, inserindo assim um elemento a mais na sentença primária "A é B", pois, "de acordo com C". Dependendo do ocorrido, elementos podem ser observados por diferentes pontos de vista e apenas na relação de uma pessoa com o ocorrido é que será estabelecida uma resposta, sem que essa seja absoluta. Essa ideia é semelhante à apresentação da tese protagoreana no 
Teeteto, mas lá a característica central é a percepção.

De acordo com os argumentos acerca de Protágoras provenientes de Platão, a tese do homem-medida está fundamentada na percepção. O homem constrói verdades a partir daquilo que ele percebe e cada indivíduo percebe de forma singular e única. Não há falsidade nas opiniões emitidas acerca das coisas porque nem é sobre a mesma coisa que está sendo emitida a opinião, dado que cada um sente à sua maneira e isso resulta numa sensação outra que não a do outro ou até mesmo a anterior, e não há nada na coisa externa a ser determinada, não há "verdades" nos elementos segundo a qual será correto ou errado afirmar algo a respeito. Cada percepção é sobre algo que é para o indivíduo, não havendo percepção do que não é, determinando que assim, a verdade está no âmbito perceptivo, e assim também o conhecimento.

Excluindo a ênfase de Platão feita à percepção, o quão confiável é o retrato de Protágoras no Teeteto? O foco do Teeteto era claramente o conhecimento, e não a tese de Protágoras, a partir da qual podemos supor que existam exacerbações daquilo que Platão acreditou ser útil para desenvolver sua crítica àqueles que tinham a percepção enquanto conhecimento. Mas a tese de Protágoras nesse diálogo não pode ser tratada apenas como um argumento irrelevante, pois se afigura possível dentro do que chegou até nós sobre o abderita. A questão da percepção enfatizada no diálogo e atribuída à Doutrina Secreta do abderita é o que propomos ser uma tese platônica da sensibilidade. Ainda é possível dizer que Platão pode ter estranhado o fato de o "homem" medida do fragmento de Protágoras não estava definido com estruturas cognitivas especificadas, percepção para sentidos, cognição para alma. Não havia distinção daquilo que no homem fazia o julgamento das experiências que lhe acometeram. Em algumas passagens do Teeteto, é possível encaixar a tradução de Schiappa quando ele substitui "das coisas que são como são" por "das coisas que são o caso". Coisas são ou não são o caso quando há alguém para medi-las. Segue um exemplo disso: quando Sócrates diz que "Uma coisa, quando se torna doce ou salgado e assim por diante, deve se tornar para alguém: não pode se tornar doce ou salgado para ninguém." (160b) Estando as coisas vinculadas umas as outras para adquirirem significados ou serem devidamente qualificadas, isso aponta um relativismo embrionário, cuja palavra ainda era ausente no vocabulário da época. Seria o caso de uma teoria emergente, latente no pensamento grego, que começou com Protágoras. A experiência, neste caso, era o que poderia ser descrita como relativa de acordo com o abderita.

Restam duas questões a serem debatidas acerca desse fragmento: considerando válido o relativismo presente no pensamento de Protágoras, seria este um relativismo que consideramos hoje como sendo "subjetivista" ou "uma ontologia positiva objetiva"? A questão é claramente posterior ao pensamento grego, mas que ainda sim pode ser definida. A primeira possibilidade, a de uma interpretação subjetivista pura, é defendida por Platão e vários estudiosos, tais como Bury, Gunthrie e Untersteiner. Na visão deles, o pensamento de Protágoras é tal que não admite a possibilidade de conhecimento, não tendo a falsidade nenhum sentido, reduzindo sua teoria a objetos físicos da senso-percepção. Os que defendem o objetivismo ontológico admitem a influência de Heráclito e afirmam que Protágoras estaria defendendo a harmonia dos opostos existentes nas coisas. Os dois logoi possíveis seriam sobre esses opostos, considerando a mudança uma parte essencial das coisas que são. O relativismo presente no fragmento do homem-medida seria, então, um logos elaborado sobre um desses opostos presentes na natureza das coisas, e não haveria necessariamente a exclusão da falsidade no discurso ou a impossibilidade do conhecimento. Se levada a cabo também todo o pensamento de Heráclito sobre o conhecimento e o logos, Protágoras estaria ciente de que a verdade dita sobre os opostos é o conhecimento sobre o que está sendo observado. Se é verdade ou não, isso depende da situação, e conhecimento e verdade 
podem ser coisas entendidas diferenciadamente. O que é verdade é o que é o caso, pois verdade para alguém, em dada situação. O que é conhecimento é saber homologar com o $\log o s$, reconhecendo a natureza dos opostos. Isso não se afigura claro nos fragmentos de Protágoras que nos chegaram, mas é uma possível interpretação, assim como também são possíveis interpretações aquelas dadas por Platão, Untersteiner, Gunthrie e os demais intérpretes.

Dado que verificamos ser essa possibilidade de influência de Heráclito válida e coerente com outros fragmentos de Protágoras, podemos dizer que essa segunda modalidade de relativismo se afigura mais pertinente. Essa perspectiva deve ser, então, reduzida a aplicações simples das experiências humanas, da relação entre coisas e humanos, dos discursos elaborados em virtude dessa relação, sobre coisas que são potencialmente mutantes entre sua natureza oposta.

\section{CONSIDERAÇÕES FINAIS}

Antes de apresentar a Doutrina Secreta, Sócrates, a partir da segunda resposta de Teeteto sobre o que é o conhecimento, introduz Protágoras, assimilando a tese do homem-medida à percepção, conteúdo principal da resposta de Teeteto. De antemão, saliento que essa aproximação é claramente uma interpretação platônica, dado que vimos as possibilidades dessa tese no contexto da época de Protágoras e nenhuma delas se restringia à percepção. Platão de imediato faz a correspondência:

Percepção, dizes, é saber? (...) Contudo, arrisca-te a não teres emitido uma definição trivial sobre o saber, mas sim aquela que diz também Protágoras. O modo é algo diferente, mas diz a mesma coisa, pois afirma que "a medida de todas as coisas" é o homem, "das que são, enquanto são, das que não são, enquanto não são". (PLATÃO, Teeteto, 151e, 152a)

Protágoras não fez menção à percepção, embora isso não seja auto excludente no enunciado de sua tese. Platão faz clara restrição da tese do homem-medida à percepção e desenvolve os argumentos posteriores tendo essa aproximação como fundamento. Platão parece ter observado que o abderita, por ter colocado a verdade no plano da relatividade, excluiu a possibilidade de um conhecimento imutável, universal, até mesmo excluindo a própria possibilidade de se obter conhecimento. Platão se posiciona frente à tese do homem-medida considerando a ideia nela transmitida como sendo de um relativismo radical, que resultaria na exclusão da falsidade e da possibilidade de conhecimento, bem como de uma verdade objetiva, e como vimos, há possibilidade de não haver intenção de Protágoras em eliminar a falsidade, pois há os que defendem o objetivismo ontológico admitindo a influência de Heráclito e afirmando que Protágoras estaria defendendo a harmonia dos opostos existentes nas coisas.

Em 152d, Platão mostra tal relativismo radical, quando afirma a impossibilidade de nomear algo, se conhecimento for tal qual a tese do homem-medida afirma. É verdade que Protágoras, ao afirmar sua tese, considerou todas as coisas (chrêmata) como sendo de uma grande amplitude, abarcando todas as experiências humanas possíveis, mas na medida em que este humano emite julgamento sobre tal experiência, admitindo esse julgamento como sendo o que é ou que não é, dado que ele é o critério (metrôn), ele não está se restringindo à percepção, mas ampliando o conceito para o campo da linguagem, do discurso. Outros fragmentos de Protágoras tratam diretamente da questão do discurso, como é o caso dos dois logoi e do logos mais fraco e mais forte. Assim, a escolha pela restrição do homem-medida para o campo apenas da percepção é uma estratégia platônica, que abre espaço para a discussão central do Teeteto. 
Portanto, Platão, na discussão que compete a obra em questão, elabora uma teoria sensista em função do propósito central da investigação sobre o conhecimento, e por isso se apropria de algumas interpretações de Protágoras de maneira a não levar ao pé da letra o que o abderita teria falado intencionalmente. Não podemos eliminar Platão do contexto principal de como elaborar Protágoras, mas é preciso saber que o ateniense, no Teeteto, tem propósitos bem específicos e isso o faz trabalhar a teoria do homemmedida com os fins voltados para a percepção e seu equivalente mundo material. No pensamento dos filósofos pré-socráticos, teorias surgiram afirmando estar tudo em movimento, havendo opostos em harmonia que compunham a ordem de tudo que aparece; o homem é aquele que pode dizer o que é o caso e o que não é o caso; mas nenhum deles atentou para o fato de que uma verdade deve ser universal, imutável, e que se o conhecimento possível está nas coisas materiais, essas coisas mudam, logo mudam também o conhecimento sobre elas. A percepção é a única ferramenta considerada nesse estudo. Perceber a natureza mutante das coisas é saber a sua verdade e assim obter conhecimento sobre tudo. Mas, perceber não implica pensar; perceber não implica predicar, perceber não gera especulações nem trabalha na dialética. Perceber é, portanto, uma ferramenta insuficiente para o conhecimento, dado que só "capta", não predica, não concatena, não especula; e além de tudo, capta aquilo que está em movimento, quando o conhecimento deve ser sobre algo imutável. Tendo observado essa grande falha e pressuposto a imutabilidade do conhecimento, Platão mostrou como a sensibilidade trabalha e por causa dessa forma de trabalhar, ela não pode ser a ferramenta única responsável pelo conhecimento.

\section{REFERÊNCIAS}

BOERI, Marcelo. Sensoperceptión y Estados Afectivos In: Do Saber ao Conhecimento: Estudos sobre Teeteto. Fabrizio Serra Editore, 2007.

BORGES, Anderson de Paula. Fluxo e Infalibilismo em Teeteto 151 - 160. Journal of Ancient Philosophy, Vol VI, 2012.

CASTRO, Roberto C. G. A Grécia Antiga e a Comunicação no século XX: aproximações. Univ. do Porto, 2013. Convenit.

CORNFORD, Francis M. Plato's theory of knowledge. New York: Liberal Arts Press, 1957.

CORDEIRO, Nestor Luis. Sendo, se é. Odysseus: São Paulo, 2011.

COSTA, Alexandre. Heráclito: Fragmentos Contextualizados. São Paulo, Odysseus, 2012.

EMPIRICUS, Sextus. Outlines of Pyrrhonism. Cambridge, Harvard University Press, 1933.

GUTIERREZ, Jose Barros. Protagoras y Gorgias: fragmentos y testimonios. Aguilar Argentina S.A. de Ediciones. Argentina, $1977-1980$.

KIRK, G. S., Raven, J. E. Os Filósofos Pre-Socráticos. Tradução de Carlos Alberto Louro Fonseca et al: Lisboa: Fundação Calouste Gulbenkian, 1979.

LAÉRCIO, Diógenes. Vidas e Doutrinas dos Filósofos Ilustres. Brasília. Ed. UnB, 1988.

PLATÃO, Teeteto. Fundação Calouste, Lisboa, 2010.

PROTAGORA. Fragmentos. In: Sofistas: testimonies y fragmentos. Trad. Antonio Melero Bellido. Madrid, Gredos, 1996.

SCHIAPPA, Edward. Protagoras and Logos. University of South Carolina Press. Columbia, South Carolina, 2003.

\section{NoTAS}

1 Tradução admitida por Michael J. O’Brien. "On every issue there are two arguments opposed to each other." 